\title{
Failure to detect Helicobacter pylori in nasal mucus in $H$ pylori positive dyspeptic patients
}

\author{
L Cellini, N Allocati, B Dainelli
}

\begin{abstract}
Stomach biopsies and samples of nasal mucus were cultured in patients with dyspeptic symptoms who underwent endoscopy to evaluate the possible route of transmission of Helicobacter pylori (H pylori). 42 patients were examined. For each patient two biopsies from the stomach corpus and antrum were taken and, before endoscopy, one nasal swab was obtained. Biopsy samples were tested for urease test, microbiological culture, and histological examination. The nasal swab was processed for microbiological examination. $H$ pylori was not found in the nasal mucus of any of the patients, including the 36 who had $H$ pylori in gastric biopsies. (f Clin Pathol 1995;48:1072-1073)
\end{abstract}

Keywords: Helicobacter pylori, nasal mucus, dyspeptic patients.

The evidence for Helicobacter pylori $(H$ pylori) as a gastrointestinal pathogen is now very strong, ${ }^{1}$ so there is a possible role for $H$ pylori in the development of gastric cancer. ${ }^{2}$ How $H$ pylori is transmitted is not yet defined. There is no known animal reservoir and the organism is likely to be spread from person to person. ${ }^{3}$ Attempts to identify natural reservoirs other than the stomach have so far proved unsuccessful. ${ }^{4}$ The organism has been detected on rare occasions in dental plaque and saliva. ${ }^{56}$ Because of overgrowth by normal autochthonous microbes in these environments, detection of $H$ pylori is not easy and the results obtained up to now have probably underestimated the true prevalence of the organism in the oral cavity. However, these sporadic findings make it unlikely that the mouth is a natural reservoir.

Recently a paper from the Gambia reported

Istituto di Medicina Sperimentale, Facoltà di Medicina, Università

"G D'Annunzio",

Via dei Vestini 31 , 66100 Chieti, Italy L Cellini

N Allocati

B Dainelli

Correspondence to: Luigina Cellini, Luigina Cellini, Sperimentale, Facoltà di Serimentale, Facoltà di Medicina, Universita "G D'Annunzio", Via dei Vestini, 31-66100 Chieti, Italy.

Accepted for publication 18 January 1995 that $H$ pylori could be isolated from human faeces. ${ }^{7}$ There may be times when the organism can be transmitted by the faecal-oral route. Epidemiological data from other countries suggest, however, that this route of transmission is not the major one. ${ }^{1}$

It is known that $H$ pylori lives in the mucus layer ${ }^{8}$ and modifies the structure of the normal mucosal surface, facilitating colonisation. The constant finding of $H$ pylori in the mucus layer has led us to search for the organism in the nasal mucus. The aim of the present study was to investigate the presence of viable $H$ pylori in the nasal mucus in dyspeptic patients.

\section{Methods}

Forty two outpatients with dyspeptic problems (24 men, 18 women; mean age 44 years, range 29-53 years) were studied.

Six biopsies, three from the antrum and three from the corpus, were taken from each patient. One biopsy from each location was drawn for a CLO test (Delta West). One biopsy from the antrum and one from the corpus for bacterial culture were placed in $0.4 \mathrm{ml}$ of brucella broth (BB, Biolife Italiana). The other specimens were fixed in $10 \%$ buffered formalin and embedded in paraffin for routine histopathological examination; $5 \mathrm{~mm}$ thick sections stained with haematoxylin and eosin ( $\mathrm{H}$ and $\mathrm{E})$ and the Giemsa procedure were examined. All examinations were performed blind.

Stomach samples were processed microbiologically within $1 \mathrm{~h}$. Biopsies for culture were trimmed with a razor, homogenised, and cultured on chocolate agar plus $1 \%$ IsoVitaleX (CA) (Becton Dickinson) and campylobacter selective medium (CSM) (Unipath). Plates were incubated under a gas mixture consisting of $85 \% \mathrm{~N}_{2}, 10 \% \mathrm{CO}_{2}$, and $5 \% \mathrm{O}_{2}$ in Campy Pak-Jar (Unipath) at $37^{\circ} \mathrm{C}$ for $5 \mathrm{~d}$. Typical $H$ pylori colonies were identified by standard methods. ${ }^{9}$

The nasal sample was taken with vigorous swabbing and was soaked in $0.4 \mathrm{ml}$ of brucella broth (Biolife) for bacterial culture. The sample was mixed and $100 \mu$ l aliquots of the solution were cultured on CA and CSM. Plates were incubated in a controlled atmosphere at $37^{\circ} \mathrm{C}$ for $5 \mathrm{~d}$. A $0.3 \mathrm{ml}$ aliquot of the remaining solution was added to $0.3 \mathrm{ml}$ of a solution containing BB plus $5 \%$ of fetal calf serum (FCS, Seromed, Biochrom) and $0.4 \%$ of Skirrow supplement (Unipath) and incubated under microaerobic conditions at $37^{\circ} \mathrm{C}$ for $24 \mathrm{~h}$. After this, $100 \mu \mathrm{l}$ aliquots were cultured as described before.

\section{Results}

The results are given in the table. $H$ pylori was recovered in the biopsies of 36 of the 42 patients examined. $H$ pylori infection was found in $77 \%$ of patients with active gastritis, $96 \%$ with duodenal ulcer, $100 \%$ with gastric ulcer, and 33\% where there was no gastritis. In two cases, $H$ pylori isolated in the gastric antrum was not found in the corpus. In one duodenal ulcer patient, histological examination revealed a helicobacter-like microorganism in the corpus but this result was not confirmed by the microbiological culture and CLO test. All samples of nasal mucus were negative on both direct and enrichment microbiological culture. 
Results of laboratory investigation in dyspeptic patients for $\mathrm{H}$ pylori, $n(\%)$

\begin{tabular}{|c|c|c|c|c|c|c|c|}
\hline \multirow{3}{*}{$\begin{array}{l}\text { Clinical condition } \\
\text { (number of patients) }\end{array}$} & \multicolumn{7}{|c|}{$\mathrm{H}$ pylori dectection with } \\
\hline & \multicolumn{2}{|c|}{ Culture of biopsy } & \multicolumn{2}{|l|}{ CLO test } & \multicolumn{2}{|l|}{ Histology } & \multirow[b]{2}{*}{ Culture of nasal mucus } \\
\hline & antrum & corpus & antrum & corpus & antrum & corpus & \\
\hline $\begin{array}{l}\text { Active gastritis } \\
\text { (13) }\end{array}$ & $10(77)$ & $9(69)$ & $10(77)$ & $9(69)$ & $10(77)$ & $9(69)$ & - \\
\hline $\begin{array}{l}\text { Duodenal ulcer } \\
(24)\end{array}$ & $23(96)$ & $22(92)$ & $23(96)$ & $22(92)$ & $23(96)$ & 23(96) & - \\
\hline $\begin{array}{l}\text { Gastric ulcer } \\
\text { (2) }\end{array}$ & $2(100)$ & $2(100)$ & $2(100)$ & $2(100)$ & $2(100)$ & $2(100)$ & - \\
\hline $\begin{array}{l}\text { No gastritis } \\
\text { (3) }\end{array}$ & $1(33)$ & $1(33)$ & $1(33)$ & $1(33)$ & $1(33)$ & $1(33)$ & - \\
\hline
\end{tabular}

\section{Discussion}

This report shows the absence of viable $\mathrm{H}$ pylori in the nasal mucus, an environment not yet investigated for the presence of this organism. These results were obtained with a selective method of isolation, and further attempts to characterise $H$ pylori from a colonised environment such as dental plaque (unpublished data) did not confirm the presence of the organism. All suspect colonies were examined with catalase, hippurate and oxidase tests but in no case was $H$ pylori confirmed.

It is difficult to isolate such a fastidious strain as $H$ pylori in a highly colonised environment. ${ }^{6}$ Microbiological isolation techniques in this environment produce less evidence of $H$ pylori than more sensitive techniques such as reverse transcription-polymerase chain reaction (RTPCR). ${ }^{5}$ Furthermore, unsuitable conditions for $H$ pylori induce its morphological conversion from the bacillary to the coccoid form. ${ }^{10}$ This "dormant" morphology is not culturable in vitro and the strain can thus be camouflaged.

In conclusion, we could not confirm the presence of viable $H$ pylori in nasal mucus, but we cannot exclude the possibility that this site may act as a transient ecological niche for the strain. More sensitive techniques such as RTPCR should be conducted to confirm whether
$H$ pylori is indeed harboured in this environment.

We thank Emanuela Di Campli, Soraya Di Bartolomeo and Wichele Masulli for the technical assistance. This work was Michele Masulli for the technical assistance. This work was supported by grant No CU.93.04315 from the Consiglio Nazionale delle Ricerche and by a grant from the Ministero del
Università e della Ricerca Scientifica e Tecnologica $(60 \%)$.

1 Lee A. The microbiology and epidemiology of Helicobacter pylori infection. Scand $\mathcal{F}$ Gastroenterol 1994;29 (suppl 201): $2-6$.

2 Parsonnet J, Friedman GD, Vandersteen DP, Chang Y, Vogelman $\mathrm{JH}$, Orentreich $\mathrm{N}$, et al. Helicobacter pylori inVogelman JH, Orentreich $\mathrm{N}$, et al. Helicobacter pylor infection and the risk

3 Malaty HM, Graham DY, Klein PD, Evans DG, Adam E, Evans DJ. Transmission of Helicobacter pylori infection. Studies in families of healthy individuals. Scand $\mathcal{F}$ Gastroenterol 1991;26:927-32.

4 Bernander S, Dalen J, Gastrin B, Hedenborg L, Lamke Lo, Ohrn R. Absence of Helicobacter pylori in dental plaques in Helicobacter pylori positive dyspeptic patients. Eur $\mathcal{F}$ Clin Microbiol Infect Dis 1993;12:282-5.

5 Nguyen HMA, Engstrand L, Genta MR, Graham DY, ElZaatari FAK. Detection of Helicobacter pylori in dental plaque by reverse transcription-polymerase chain reaction. plaque by reverse transcription-p

6 Ferguson DA, Li C, Patel RN, Mayberry RW, Chi SD, Thomas E. Isolation of Helicobacter pylori from saliva. $\mathfrak{f}$
Thom

7 Tomas JE, Gibson GR, Darboe MK, Dale A, Weaver LT. Isolation of Helicobacter pylori from human faeces. Lancet 1992;340:1194-5.

8 Sidebotham RL, Baron JH. Hypothesis: Helicobacter pylori, urease, mucus, and gastric ulcer. Lancet 1990;335:193-5.

9 Hazell SL. Cultural techniques for the growth and isolation of Helicobacter pylori. In: Goodwin CS, Worsley BW, eds. Helicobacter pylori: biology and clinical practice. Boca $\mathrm{Ra}$ ton, Florida: CRC Press, 1993:273-83.

10 Cellini L, Allocati N, Di Campli E, Dainelli B. Helicobacter pylori: a fickle germ. Microbiol Immunol 1994;38:25-30. 